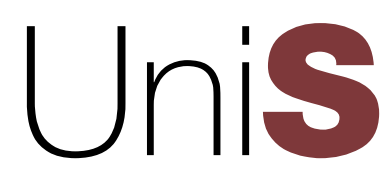

\title{
University of Surrey
}

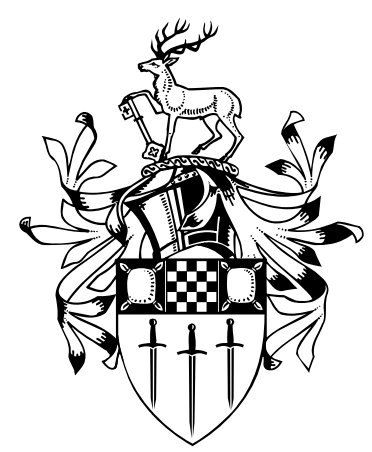

Discussion Papers in Economics

DETERMINANTS OF EMPLOYEE CRIME IN THE UK

By

Neil Rickman

(University of Surrey \& CEPR)

$\&$

Robert Witt

(University of Surrey)

DP 07/03

Department of Economics

University of Surrey

Guildford

Surrey GU2 7XH, UK

Telephone $+44(0) 1483689380$

Facsimile +44 (0)1483 689548

Web www.econ.surrey.ac.uk 


\title{
The determinants of employee crime in the $\mathrm{UK}^{*}$
}

\author{
Neil Rickman \\ Robert Witt \\ University of Surrey \\ University of Surrey \\ and CEPR
}

June 16, 2003

\begin{abstract}
For the first time, we present evidence on employee theft in the UK using data on actual recorded crime. We present a model where employees are 'rational cheaters' with 'consciences' to produce hypotheses about the role of labour market (wages, unemployment) and social (age, education) influences on employee theft. We then examine the role of these influences using regional crime data supplemented by data from the LFS. Our results provide information on two competing views of motivations for crime and on policy to combat employee crime.
\end{abstract}

JEL Classification: J20, K14, K42, M5

Keywords: Employee crime, Labour markets

${ }^{*}$ We are grateful to Steve Machin for advice concerning the LFS data and to Paul Barnes. Any errors are our own. 


\section{Introduction}

Following Becker (1968)'s pioneering work, economists have been interested in the study of criminal behaviour. This work has covered theoretical issues in optimal deterrence (see Garoupa (1997) and Polinsky and Shavell (2000)) and empirical causes of this activity (for example, Witt et al. (1999) and Machin and Meghir (2000)). Researchers have uncovered important links between economic activity and types of crime. For example, Field (1999) finds that rates of property crime growth are highly correlated with economic growth while Fajnzylber et al. (2002) establish a relationship between income inequality and violent crime across countries. A notable gap in this work, recognised in 1989 by Dickens et al. (1989), relates to employee (or "occupational") crime, which the Association of Certified Fraud Examiners (ACFE) defines as "the use of one's occupation for personal enrichment through the deliberate misuse or misapplication of the employing organisation's assets." (ACFE (2002), p. 2). The aim of this paper is to provide evidence on a particular area of this crime: employee theft in the UK.

Employee theft constitutes a significant portion of crimes committed against businesses (by employees and others). In the US, Dickens et al. (1989) reported transfers from businesses to workers of up to $\$ 56$ billion in 1989 . More recently, ACFE (2002) attributes $87 \%$ of employee crime to "asset mis- 
appropriations", with a median cost of $\$ 80,000$. Recent evidence in the UK also suggests a serious problem of employee theft. Although such offences recorded in England and Wales peaked in 1979, there has been a steady rise in the employee theft rate, from around 29 crimes per 100,000 people in 1995/96 up to around 33 crimes per 100,000 population by 1999/00. A British Chambers of Commerce (BCC) survey (BCC (2002)) identified 12\% of crimes against its members as employee theft while research for the Scottish Executive (Burrows et al. (2002)) indicated that 9\% of firms across five single-digit SIC industries suffered from this form of crime in 1998, on a total of 26,812 occasions. Costings are not available but the BCC estimates that crime against its members cost the UK $£ 19$ billion in 2001 , and the $12 \%$ of employee theft will contribute significantly to this. ${ }^{1}$

Conceptually, Nagin et al. (2002) contrast three approaches to modelling crime, regardless of type. The "rational cheater" model assumes that employees and employers commit and monitor crime on the basis of a familiar cost-benefit calculus. Dickens et al. (1989) and White (1992) both discuss the causes of employee crime in this context. Alternatively, criminological and psychological literature postulates a "conscience model" (where criminal activity is the result of failing to care about acting illegally) and an "im-

\footnotetext{
${ }^{1}$ Of course, these direct costs are not the only ones associated with employee theft: in addition to these, it is evident that firms spend scarce resources monitoring employees and detecting crime. See Dickens et al. (1989), ACFE (2002) and Barnes and Lambell (2002).
} 
pulse control" model (where the immediacy of gains from crime outweigh any longer term potential costs). A number of authors have sought to test various implications of these approaches, in contexts beyond employee crime. Thus, Nagin and Paternoster (1993) and Nagin et al. (2002) find evidence to support rational cheater and conscience models in contexts of general crime and employee responses to incentive schemes. Barnes and Lambell (2002) examine the determinants of employee crime in a rational cheater model. They find systematic variations in perceived susceptability to fraud (linked to industry, organisational size and type, and respondent's role). They interpret their findings as supporting the model in question.

As already mentioned, the focus of our paper is employee theft in the UK. In particular, to motivate our empirical work, we present a model of employee theft that combines two of the above approaches: employees are rational cheaters but they are also motivated by their innate "propensity to offend" (Nagin and Paternoster (1993))-i.e. an element of conscience. We then examine the implications of this on a unique set of data containing regional information on employee theft between the financial years 1995/96 and 1999/00. Bearing in mind our model, we have augmented these data with regional information from the LFS to produce a data set capable of examining the role of labour markets, education and age in the employee crime decision. The paper's main contribution is the use of these data on recorded crime to 
examine the determinants of employee theft. Of the studies mentioned above, only Nagin et al. (2002) have data on observed economic behaviour (though not relating to employee theft). The others use experimental data and survey evidence on perceptions of employee crime, both of which could fail to reflect actual behaviour in the workplace. In contrast, ours is the first paper seeking to analyse data on recorded employee thefts. In addition, we provide a rare examination of this issue in the UK and provide fresh information on the extent to which rational cheating and conscience combine to influence the decision to commit crime.

The paper is structured as follows. The next section presents a model of individual employee crime that suggests several potential influences on employee crime. Then, Section 3 describes our data and methods before Section 4 presents the results. Section 5 concludes the paper.

\section{The model}

In order to consider potential influences on employee crime we examine a model of the individual employee's crime decision. Consider an area $k$, with $I^{k}$ workers. We model employee $i \in I^{k}$ 's crime decision as a two-stage one. In the first stage, she decides whether to commit a crime, then she decides 
how much crime to commit. ${ }^{2}$ The model is solved by backwards induction, with the crime level decision being taken conditional on choosing to commit a crime, and the crime decision being taken in anticipation of this.

If the employee commits a crime, her (risk neutral) expected utility is

$$
E U_{i}^{C}=p\left(e_{i}\right)\left(w_{i}+e_{i}\right)+\left[1-p\left(e_{i}\right)\right] v_{i} \bar{w}_{i}-\psi\left(e_{i}, x_{i}\right)
$$

where we have suppressed $k$ for convenience. In (1), $w_{i}$ is the employee's current wage, $v_{i}$ is her probability of outside employment if the crime is detected (since this results in dismissal and no wage), $\bar{w}_{i}$ is the outside wage, $p\left(e_{i}\right)$ is the probability of non-detection which is dependent on the employee's crime volume $\left(e_{i}\right)$ (we assume $\left.p_{e_{i}}<0, p_{e_{i} e_{i}}>0\right)^{3}, \psi\left(e_{i}, x_{i}\right)$ is the cost of committing crime to the employee and $x_{i}$ is her "propensity to commit crime" (Nagin et al. (2002) also refer to this as the employee's "conscience"): we assume $\psi_{e_{i}}, \psi_{e_{i} e_{i}}>0, \psi_{x_{i}}, \psi_{e_{i} x_{i}}<0$. Possible determinants of $x_{i}$ are considered below but, as one example, it may be influenced by the employee's age, with

\footnotetext{
${ }^{2}$ Our focus on the potential criminal's decision does not endogenise the employer's monitoring strategy. In fact, it is readily shown that the predictions in Proposition 1 below are consistent with a Nash equilibrium in crime and monitoring (since this produces ambiguous comparative statics). Effectively, we are assuming that employee effects would dominate in such a set-up. There is some empirical support for this view. Barnes and Lambell (2002) find that variations in employer monitoring activity do not influence susceptibility to employee crime while in the ACFE's survey ACFE (2002), $76 \%$ of cases were attributed to a lack of, or an "ignored", monitoring system. Finally, White (1992) shows that even in a world of complete information with timely monitoring, employee crime would be observed.

${ }^{3}$ We could add the employer's monitoring effort by assuming $p(e, m), p_{m}<0$.
} 
younger employees being more likely to consider committing crime (i.e. they would have a higher $x_{i}$ ).

Following Nagin and Paternoster (1993), we assume that employees may differ with respect to their initial propensity to offend. Employers are aware of this heterogeneity but do not observe (perfectly) the individual $x_{i}$ 's.

The first-order and second-order conditions for $e_{i}$ are

$$
\begin{gathered}
p_{e_{i}}\left(w_{i}+e_{i}-v_{i} \bar{w}_{i}\right)-\psi_{e_{i}}=0 \\
p_{e_{i} e_{i}}\left(w_{i}+e_{i}-v_{i} \bar{w}_{i}\right)+p_{e_{i}}-\psi_{e_{i} e_{i}} \leq 0
\end{gathered}
$$

respectively. Equation (2) defines the individual crime level $e_{i}^{*}\left(w_{i}, v_{i}, \bar{w}_{i}, x_{i}\right)$. An employee who chooses not to commit crime receives their wage $w_{i}$. Thus, (anticipating $\left.e_{i}^{*}\right)$ the employee will commit crime iff $E U_{i}^{C}\left(e_{i}^{*}\right)>w_{i}$. This implicitly defines $\hat{x}_{i}$ :

$$
p\left(e_{i}^{*}\right)\left(w_{i}+e_{i}^{*}\right)+\left[1-p\left(e_{i}^{*}\right)\right] v_{i} \bar{w}_{i}-\psi\left(e_{i}^{*}, \hat{x}_{i}\right) \equiv w_{i}
$$

Hence, the volume of crime committed by the individual employee (in area $k)$ is

$$
C_{i}^{k}= \begin{cases}e_{i}^{* k}\left(\cdot, x_{i}^{k}\right) & \text { if } x_{i}^{k}>\hat{x}_{i}^{k} \\ 0 & \text { if } x_{i}^{k}<\hat{x}_{i}^{k}\end{cases}
$$


From (2), we have ${ }^{4}$

$$
\begin{gathered}
\frac{\partial e_{i}^{*}}{\partial w_{i}}=-\frac{1}{\bar{w}_{i}} \frac{\partial e_{i}^{*}}{\partial v_{i}}=-\frac{p_{e_{i}}}{p_{e_{i} e_{i}}\left(w_{i}+e_{i}-v_{i} \bar{w}_{i}\right)+p_{e_{i}}-\psi_{e_{i} e_{i}}}<0 \\
\frac{\partial e_{i}^{*}}{\partial x_{i}}=\frac{\psi_{e_{i} x_{i}}}{p_{e_{i} e_{i}}\left(w_{i}+e_{i}-v_{i} \bar{w}_{i}\right)+p_{e_{i}}-\psi_{e_{i} e_{i}}}>0, \forall x_{i} \geq \hat{x}_{i}
\end{gathered}
$$

Now, from (3)

$$
\frac{\partial \hat{x}_{i}}{\partial w_{i}}=-\frac{1}{\bar{w}_{i}} \frac{\partial \hat{x}_{i}}{\partial v_{i}}=-\frac{1}{v_{i}} \frac{\partial \hat{x}_{i}}{\partial \bar{w}_{i}}=\frac{p_{i}-1}{\psi_{x_{i}}}>0
$$

These results give the following proposition:

Proposition 1 Lower wages, higher prospects of outside employment and higher propensities to commit crime all make an employee more likely to commit crime and increase the volume of crime committed by existing criminals, ceteris paribus. The opposite also holds.

It is clear from (4) that some employees will choose to commit crime while others will not. Equations (5)-(7) tell us how these choices are affected by labour market variables and individual attitudes towards crime. Higher wages and higher chances of re-employment both increase a criminal's volume of crime, as does a higher propensity for crime. Further, these changes

\footnotetext{
${ }^{4}$ Note that we do not present results on $\bar{w}$ as we do not have data on this below.
} 
also make a given employee more likely to commit crime in the sense that her threshold $\hat{x}_{i}$ falls. The intuition behind these results is clear. Rational workers will not risk detection and firing, should they commit a crime, unless the opportunity cost is low. In our case, this means that their current wage rate is low or the prospects of re-employment are high.

We might also provide some intuition for the role of $x$ by describing some of its potential determinants: these will also be required to proxy $x$ in our empirical work. Nagin and Paternoster (1993) relate "conscience" to the idea of "social bonds" which, in turn, can be related to the concept of "social capital" (see Glaeser et al. (2002)). Thus, if we can find variables linked to social capital formation, they may provide useful proxies for $x$. Glaeser et al. present evidence that age and education are both positively related to social capital. ${ }^{5}$ Bearing this in mind, we suggest that $x$ is negatively related to age and education (recall that higher $x$ makes crime more likely) and we use these in our empirical work below. Again, the intuition is uncomplicated: having 'invested' in the existing social structure, the elderly and the better educated are less inclined to break the rules underpinning it.

Before moving on, we note that the empirical analysis below makes use

\footnotetext{
${ }^{5}$ In fact, they find a quadratic (inverse-U) relationship between age and social capital with a turning point at about 50 years of age. Thus, for most employment ages, social capital and age are positively related. More generally, for a detailed discussion of how education can reduce crime, see Lochner and Moretti (2001).
} 
of aggregate (police force area) data. It is clear, however, that the influences on crime that we have identified will remain at this level: the expression for aggregate employee crime in area $k$ is $C^{k}=\sum_{i \in I^{k}} C_{i}^{k}$ and it immediately follows from (4) that this depends on wages, unemployment and the determinants of $x$, just as the individual crime decision does. Of course, as Koebel (2002) makes clear, the conditions under which individual decisions will be mirrored in aggregate data are reasonably restrictive so we should be careful when interpreting our empirical results. As he continues, however, theory remains essential for determining the variables of interest in the aggregate data set (see p. 251) — precisely the sense in which we use our model.

\section{Data and methods}

Our model suggests that the employee's decision to commit theft at work will be influenced by a mixture of labour market and social factors. In particular, data on employee crime may be linked with wages and unemployment, as well as with individual influences like age and educational attainment. It also suggests that these influences will continue to be relevant at the aggregate level. We now discuss our data on each of these variables.

While we do not have individual data on employee crime, we do have regional information on employee theft. To examine the effects of the variables 
in our model we use aggregated police force area data. ${ }^{6}$ All 43 police force areas in England and Wales were originally included, but after aggregating the City of London and Metropolitan regions (due to low population in the City of London) and combining Gwent and South Wales (due to a boundary change), we are left with 41 areas. The empirical analysis to be subsequently presented is based on pooled cross-section and time-series observations of 41 police force areas from the financial year 1995/96 to 1999/00. Although police force statistics go back many years before 1995 it is very difficult to find regional data on one of our variables, education, for earlier years. Hence this exercise is constrained by data availability.

The data on employee theft used in this paper are compiled by the Home Office. Theft by an employee is defined in part of Section 1 of the Theft Act $1968 .^{7}$ We calculate an employee theft rate on the basis of population estimates by police force area supplied by the Office for National Statistics. The labour market and demographic measures come from aggregating individual-level data to police force area using the quarterly UK Labour Force Survey (LFS). From 1995Q2 onwards, we are able to match individuals using

\footnotetext{
${ }^{6}$ Because we focus on only one category of crime such aggregation will not create the biases discussed by Cherry and List (2002).

7 "The theft should be known at the time of recording to have been by an employee or group of employees. The owner of the property stolen should be the employee's employer": see the Home Office Counting Rules for Recorded Crime (2002) at http://www.homeoffice.gov.uk/rds/countrules.html.
} 
a county level identifier to the police force area. Unfortunately, the county identifier was removed from the data files after 1999Q3, and, therefore, our estimation sample is restricted to five years.

We now turn to the two important incentive variables; expected outside employment (to measure $v$ from our model) and the employee's wage (capturing $w$ ). Our area unemployment rate is derived from the LFS by dividing the unemployed (International Labour Organisation definition) by those individuals who are economically active. ${ }^{8}$ In computing area level data on wages from the LFS, observations for men's wages are restricted to workers aged between 18 and 65. Observations for women's wages are restricted to workers aged between 18 and 60 . We derive hourly pay by dividing the gross weekly wage by the usual weekly paid hours including paid overtime. These wages are then deflated by the retail price index. The model outlined above predicts that high wage rates reduce crime by increasing its opportunity cost. ${ }^{9}$

In addition to our labour market measures, we include demographic controls that are assumed to be related to an individual's "propensity to commit crime", namely education and age (i.e. proxies for $x$ ). Area level data on ed-

\footnotetext{
${ }^{8}$ Of course, a number of other factors beyond the local unemployment rate will help determine an employee's probability of re-employment. However, the unemployment rate will have an important role to play and is the main measure available in the LFS.

${ }^{9}$ Freeman (1996), Gould et al. (2000), Grogger (1998), Machin and Meghir (2000), and Viscusi (1986) establish a negative correlation between earnings levels (or wage rates) and criminal activity in general.
} 
ucation is sparse in the UK, but the LFS does contain individual data on the number of qualifications held. However, given the difficulties of identifying every qualification in the LFS questionnaire, we derive the population share of those with no educational qualifications. ${ }^{10}$ The variable for the proportion of the population in a police force area with no education qualifications is designed to measure the possible opportunity cost associated with criminal activity.

Table 1 reports summary statistics for this set of 41 police force areas. From the first row of the table it can be seen that employee theft numbers vary widely across police force area and year, varying from 13 offences per 100,000 of the population to around 70 per 100,000 of the population in a single year (London in 1997/98). The second interesting feature of the data is that the percentage of the population with no educational qualifications varies widely between police force area and year from 8\% (Surrey in 1999/00) to $25 \%$ (West Midlands in $1995 / 96$ ).

The previous section suggests an equation for employee crime in area $k$ of the form: form:

$$
C^{k}=C^{k}\left(v^{k}, w^{k}, e d u^{k}, a g e^{k}\right)
$$

\footnotetext{
${ }^{10}$ For a detailed discussion of the academic and vocational qualifications contained in the LFS, see Dearden et al. (2002).
} 
where we postulate that $x=g(e d u, a g e) .{ }^{11}$ Also, to deal with the possibility of persistence in the level of employee crime (for example, 're-offending' may occur), we amend the current model to provide a dynamic setting in which such persistence may arise. ${ }^{12}$ Therefore, we consider a dynamic specification including the lagged crime rate (an autoregressive panel data model) of the form

$$
\tilde{C}_{t}^{k}=\beta \tilde{v}_{t}^{k}+\gamma \tilde{w}_{t}^{k}+\delta e d u_{t}^{k}+\phi a g e_{t}^{k}+\theta \tilde{C}_{t-1}^{k}+\eta^{k}+\mu_{t}^{k}
$$

for $k=1, \ldots, 41$ and $t=2, \ldots, 5$, where $\tilde{C}$ is the $\log$ of employee crime rate, $\tilde{v}$ is the log of unemployment rate, $\tilde{w}$ is log average wage rate, $e d u$ is the share of the population with no educational qualifications, age is the average age and where $|\theta|<1$ and $\epsilon_{t}^{k} \equiv \eta^{k}+\mu_{t}^{k}$ is the usual fixed effects decomposition of the error term, i.e. $\eta^{k}$ is an unobserved police force areaspecific time-invariant effect which allows for heterogeneity in the means of the crime series across areas and $\mu_{t}^{k}$ is a disturbance term assumed to be independent across areas. ${ }^{13}$

To estimate the empirical equation above, two primary issues have to

\footnotetext{
${ }^{11}$ If the relationship in $g(\cdot)$ held perfectly, the employer would be able to observe $x$, contrary to our assumption. In fact, there will be some noise associated with our empirical proxies for $x$. Further, even if the employer could infer likely criminal behaviour from $g(\cdot)$, it would be illegal to discriminate against a given employee in terms of monitoring on the basis of age and education-beyond normal probationary training, etc.

${ }^{12}$ Rob and Zemsky (2002) provide an interesting model where social capital grows/shrinks through the similar notion of "re-shirking" in a corporate setting.

${ }^{13}$ Notice that at the individual level, Proposition 1 predicts $\beta<0, \gamma<0, \delta>0$, and $\phi<0$.
} 
be confronted. First, while the equation controls for fixed effects, it does not allow for the possible endogeneity of labour market variables, and so the results cannot be given a causal interpretation. Fajnzylber et al. (2002) summarize the problems posed by the use of such methods when modelling violent crime. Second, it is possible that employee crime rates are measured with error, and this error may be correlated with some of the regressors. To assess the effects of both endogeneity and measurement error we implement a GMM difference estimator.

\section{Results}

Table 2 presents OLS estimates of the crime equation in levels and within groups. Most of the coefficients in the levels regression are not significantly different from zero. The two exceptions are the lagged dependent variable and age. Area crime rates show a sizeable degree of persistence with an estimate of 0.76 that is highly significant. Age is significant at the 10-percent level, with a one-year increase in average age decreasing employee crime by about $4 \%$ in the short-run. The unemployment rate and age have negative coefficients as suggested by the theoretical model, but are not significant. The wage rate is neither significant nor correctly signed, according to the model. The second column of Table 2 presents within-groups estimates, i.e. all variables 
are expressed in deviations from their area specific means (taken over time). The within-groups estimates for area crime rates are quite different from the OLS results. For the lagged dependent variable, the estimate is reduced to 0.25 suggesting much less persistence in area crime rates. ${ }^{14}$ The tests of second-order serial correlation in the residuals for OLS levels and in the first-differenced residuals for the within groups estimator are in both cases consistent with the maintained assumption of no serial correlation in $\epsilon_{t}^{k}$.

The results in the second column of Table 2 suggest that fixed effects are indeed important. In moving from the OLS results to the within-groups estimates the coefficient on unemployment increases in absolute terms from -0.054 to -0.197 . From the within-groups estimates we see that all effects are consistent with those suggested in Section 2, although wage, education and age do not have a significant impact. The fact that other variables are not significant suggests that the OLS estimates might be biased downwards for two reasons. First, the OLS and within-groups results do not control for the joint endogeneity of some of the explanatory variables. It is likely that the incidence of employee theft not only is driven by but also affects a number of labour and demographic variables. For example, crime may affect an

\footnotetext{
${ }^{14}$ As expected in the presence of area-specific effects, OLS levels appears to give an upwards-biased estimate of the coefficient on the lagged dependent variable, whilst the within-groups estimate appears to give a downwards-biased estimate of this coefficient (see Bond (2002)).
} 
individual's human capital acquisition and, then, affect earnings potential as well. Second, measurement error in the employee theft series might be correlated with some of the explanatory variables, particularly wage rates.

To deal with endogeneity and to eliminate the area-specific effect, we firstdifference the crime equation and estimate with GMM, using lagged levels of crime, unemployment, wage and education as instruments. These results are shown in column 1 of Table 3 . The result is to increase the coefficient on unemployment and to increase substantially the estimate on the wage variable. The coefficient on the lagged dependent variable is only 0.27 , and the elasticity of crime with respect to wage is around 2.0, suggesting a high opportunity cost of illegal behaviour. The null hypothesis of no second order serial correlation cannot be rejected. Taking a look at the Sargan test, the $p$-value indicates that the instruments are not rejected. However, this does not mean the instruments are informative and strong. ${ }^{15}$ To address this concern, we use the system-GMM estimator in column 2. Using differences as instruments for the levels substantially improves the precision of our estimates, and the extended set of moment restrictions is not rejected by the Sargan test of over-identifying restrictions.

\footnotetext{
${ }^{15}$ Indeed, in unreported results, we find that weak instruments cannot be rejected using the partial $\mathrm{R}^{2}$ or first-stage F-statistic criteria. If the instruments used in the first differenced equations are weak, then the results should be biased in the direction of withingroups (see Blundell and Bond (2000)).
} 
All our coefficients have signs which are consistent with the hypotheses in Section 2 and are all significant. The coefficient on the lagged dependent variable is 0.52 , and the elasticity of crime with respect to wage is a more plausible 0.6. The effect of unemployment is consistently negative across all regressions, and is highly significant in the system-GMM estimator. The elasticity of crime with respect to unemployment is roughly 0.75 . The share of the population with no educational qualifications has a positive and strongly significant coefficient. This is consistent with our theoretical model. Given that older people are less likely to engage in criminal activity, a negative correlation is anticipated between average age and crime (as Proposition 1 predicts). Our results indicate that age is strongly significant and correctly signed.

\section{Conclusions}

Despite considerable interest from economists in the relationship between economic activity and criminal behaviour, little attention has been paid to the determinants of employee crime. This is despite that fact that surveys on both sides of the Atlantic suggest that such crime costs the economy billions each year (in direct and indirect-monitoring - costs). Only Barnes and Lambell (2002) produce econometric work in this area but they rely on 
organisations' "perceptions" of their susceptability to crime. The results are valuable but are open to natural questions about the reliability of reporting and whether different interviewees could have different perceptions of the issue at hand. For the first time, this paper seeks to examine the determinants of employee crime (specifically theft) from recorded crime data.

To motivate our empirical work, we use a model where 'rational cheaters' are also motivated by conscience when deciding whether to commit crime. Our predictions suggest that wage levels and unemployment will have similar qualitative effects on employee thefts (with increases in both serving to lower crime rates) while 'social' influences (from age and education) are also predicted to influence crime: older, better educated individuals being less likely to commit crime. Our econometric results support these predictions. We also find evidence of persistence in employee crime.

These results have two sets of implications. First, they support findings in work by Nagin and others (e.g. Nagin and Paternoster (1993) and Nagin et al. (2002)) that suggest criminal activity is generated by more than simple economic influences. While employees are apparently 'rational cheaters', motivated by the incentives to remain employed at a good wage, our model and results also suggest a role for individual conscience and desire to support existing social structures and rules when they are making decisions about crime. This result may have implications for theories of social capital forma- 
tion and for the modelling economic activity (at least in relation to crime). The second implication of our results concerns potential policies that may help address employee crime. In common with other work on the relationship between economic activity and crime, we find a role for labour market conditions in the crime decision. However, to the extent that low unemployment and high wages are linked, this relationship is not a simple one. Our results also suggest a role for broader social policies which may encourage employees to regard their job as being part of their wider social setting.

Although our use of recorded crime data is new, there are several questions that cannot be addressed with data at the level of aggregation currently available in the UK. This immediately suggests a need for more detailed data collection (through official or research channels) in order to help us understand employee crime. It would be useful to examine the break-down in crime by industry and region and also to consider the role played by monitoring technology used by employers. Further, of course, individuallevel data would allow aggregation questions to be immediately addressed and, thereby, enable direct testing of individual-level models of employee crime. In this way, a relatively neglected, but economically significant, area of crime could be better understood. The current paper has sought to help begin this process. 


\section{References}

ACFE (2002). 2002 Report to the Nation: Occupational Fraud and Abuse. Association of Certified Fraud Examiners, Austin, Texas.

Barnes, P. and Lambell, J. (2002). Organisational susceptability to fraud: Does fraud strike randomly or are there organisational factors affecting its likelihood and size? Working Paper, Nottingham Business School.

BCC (2002). Securing Enterprise: A Framework for Tackling Business Crime. British Chambers of Commerce, London.

Becker, G. (1968). Crime and punishment: An economic approach. Journal of Political Economy, 76, 169-217.

Blundell, R. and Bond, S. (2000). GMM estimation with persistent panel data: An application to production functions. Econometric Reviews, 19, $321-340$.

Bond, S. (2002). Dynamic panel data models: Aguide to micro data methods and practice. Cemmap Working Paper.

Burrows, J., Andrews, S., Bamfield, J., Hopkins, M., and Ingram, D. (2002). Crime Against Business in Scotland. Scottish Executive Central Research Unit, Edinburgh. 
Cherry, T. L. and List, J. A. (2002). Aggregation bias in the economic model of crime. Economics Letters, 75, 81-86.

Dearden, L., McIntosh, S., Myck, M., and Vignoles, A. (2002). The returns to academic and vocational qualifications in britain. Bulletin of Economic Research, 54(3), 249-274.

Dickens, W. T., Katz, L. F., Lang, K., and Summers, L. H. (1989). Employee crime and the monitoring puzzle. Journal of Labour Economics, 7(3), 331347.

Fajnzylber, P., Lederman, D., and Loayza, N. (2002). What causes violent crime? European Economic Review, 46, 1323-1357.

Field, S. (1999). Trends in Crime Revisited. Home Office Research Study No. 195, London.

Freeman, R. (1996). Why do so many young American men commit crimes and what might we do about it? Journal of Economic Perspectives, 10(1), $25-42$.

Garoupa, N. (1997). The theory of optimal law enforcement. Journal of Economic Surveys, 11, 267-295.

Glaeser, E. L., Laibson, D., and Sacerdote, B. (2002). An economic approach to social capital. Economic Journal, 112(483), F437-F458. 
Gould, E., Mustard, D., and Weinberg, B. (2000). Crime rates and local labor market opportunities in the United States: 1979-1997. Working Paper.

Grogger, J. (1998). Market wages and youth crime. Journal of Labour Economics, 16(4), 756-791.

Koebel, B. M. (2002). Can aggregation across goods be achieved by neglecting the problem? Property inheritance and aggregation bias. International Economic Review, 43(1), 223-255.

Lochner, L. and Moretti, E. (2001). The effect of education on crime: Evidence from prison inmates, arrests, and self-reports. Working Paper.

Machin, S. and Meghir, C. (2000). Crime and economic incentives. Working Paper, Department of Economics, University College London.

Nagin, D. S. and Paternoster, R. (1993). Enduring individual differences and rational choice theories of crime. Law and Society Review, 27(3), 467-496.

Nagin, D. S., Rebitzer, J. B., Sanders, S., and Taylor, L. J. (2002). Monitoring, motivation and management: The determinants of opportunistic behaviour in a field experiment. American Economic Review, 92(4), 850873.

Polinsky, M. and Shavell, S. (2000). The economic theory of public enforcement of law. Journal of Economic Literature, 38, 45-76. 
Rob, R. and Zemsky, P. (2002). Social capital, corporate culture and the incentive intensity. RAND Journal of Economics, 33(2), 243-257.

Viscusi, W. K. (1986). Market incentives for criminal behaviour. In R. Freeman and H. Holzer, editors, The Black Youth Employment Crisis. University of Chicago Press, Chicago.

White, W. D. (1992). Information and the control of agents. Journal of Economic Behaviour and Organisation, 18, 111-117.

Witt, R., Clarke, A., and Fielding, N. (1999). Crime and economic activity: A panel data approach. British Journal of Criminology, 39(3), 391-400. 
Table 1: Descriptive statistics for 41 Police Force Areas, 1995/96-1999/2000

\begin{tabular}{|l|l|l|l|l|l|}
\hline \multicolumn{2}{|c|}{ median mean } & \multicolumn{2}{c}{ stan.dev. $\operatorname{min.}$} \\
\hline Employee theft per 100,000 pop'n & 26.37 & 27.97 & 9.05 & 13.05 & 69.37 \\
\hline Unemployment rate (\%) & 6.06 & 6.26 & 2.21 & 2.17 & 14.11 \\
\hline Average hourly wage (f) & 7.37 & 7.65 & 1.05 & 6.07 & 11.66 \\
\hline $\begin{array}{l}\text { Share of Population with no } \\
\text { educational qualifications }\end{array}$ & 0.163 & 0.166 & 0.037 & 0.080 & 0.250 \\
\hline Average Age (years) & 39.10 & 39.12 & 0.65 & 37.27 & 40.92 \\
\hline
\end{tabular}

The sample contains police force areas with 5 years of complete data. The number of police force areas in the sample is 41 for a total number of 205 observations. 
Table 2: OLS Estimates of Employee Crime

\begin{tabular}{|c|c|c|c|c|}
\hline & \multicolumn{2}{|c|}{ LEVELS } & \multicolumn{2}{|c|}{ WITHIN-GROUPS } \\
\hline & Estimate & $\mathrm{SE}$ & Estimate & $\mathrm{SE}$ \\
\hline Log Unemployment Rate & -0.0540 & 0.0616 & -0.1970 & 0.0859 \\
\hline Log Average Real Hourly Wage & 0.2141 & 0.1854 & -0.0459 & 0.3508 \\
\hline $\begin{array}{l}\text { Share of Population with No Educational } \\
\text { Qualifications }\end{array}$ & 0.4050 & 0.5772 & 0.8275 & 0.7910 \\
\hline Average Age & -0.0393 & 0.0231 & -0.0170 & 0.0540 \\
\hline Lagged Dependent Variable & 0.7605 & 0.0492 & 0.2482 & 0.1099 \\
\hline Police Force Area Fixed Effects & \multicolumn{2}{|c|}{ No } & \multicolumn{2}{|c|}{ Yes } \\
\hline R-Squared & \multicolumn{2}{|c|}{0.7036} & \multicolumn{2}{|c|}{0.5359} \\
\hline \multirow[t]{2}{*}{ Sample size } & \multicolumn{2}{|c|}{164} & \multicolumn{2}{|c|}{164} \\
\hline & \multicolumn{4}{|c|}{ DIAGNOSTIC TESTS ( $p$-values) } \\
\hline First-Order Serial Correlation & \multicolumn{2}{|c|}{0.898} & \multicolumn{2}{|c|}{0.003} \\
\hline Second-Order Serial Correlation & \multicolumn{2}{|c|}{0.366} & \multicolumn{2}{|c|}{0.633} \\
\hline
\end{tabular}

Notes:

1. The dependent variable is Log(employee theft/population).

2. Standard errors are robust to heteroskedasticity.

3. The tests for serial correlation in the residuals is asymptotically distributed as $\mathrm{N}(0,1)$ under the null of no serial correlation. 
Table 3: GMM Estimates of Employee Crime

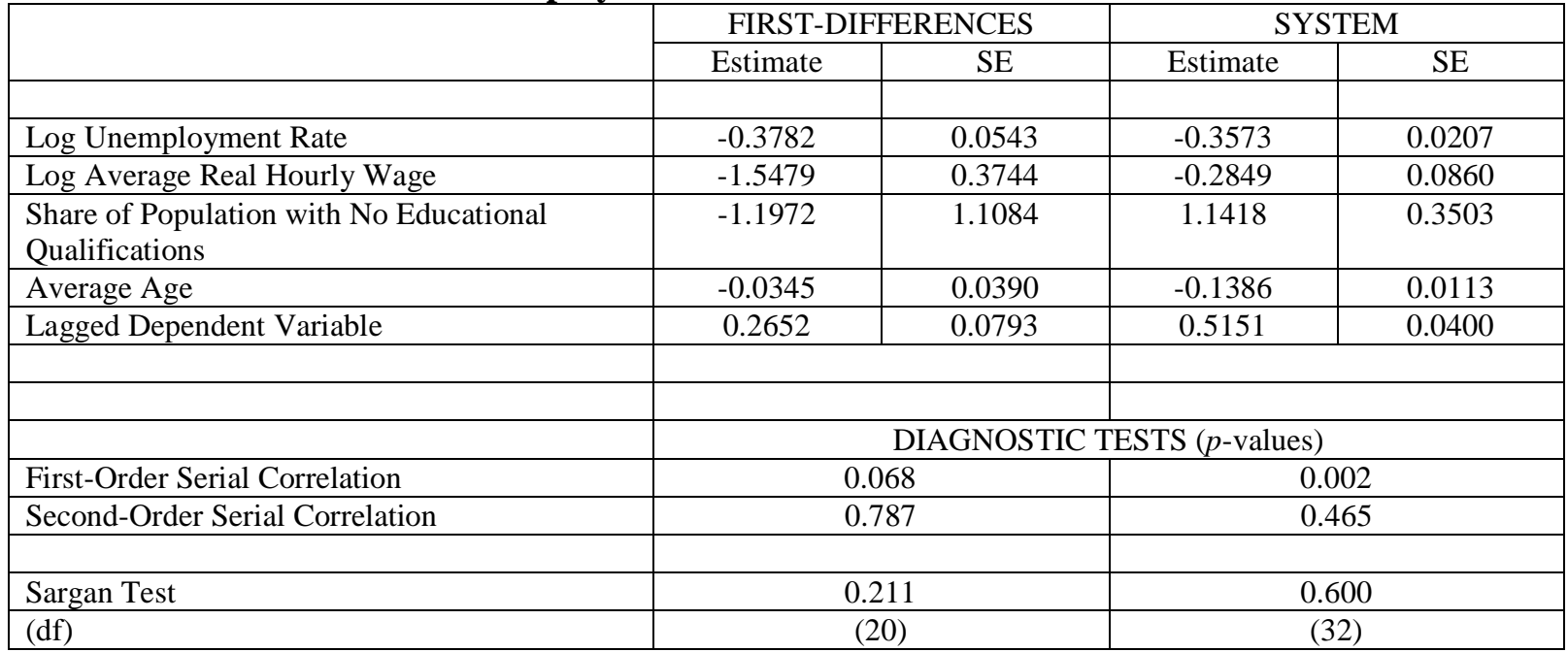

Notes:

4. Standard errors are robust to heteroskedasticity.

5. The results reported here are based on two-step GMM estimators. All computations are done using DPD98 for Gauss: see Arellano, M. and Bond, S. (1998): Dynamic Panel Data Estimation Using DPD98: A Guide for Users. Oxford University Press: Oxford.

6. The tests for serial correlation in the residuals is asymptotically distributed as $\mathrm{N}(0,1)$ under the null of no serial correlation.

7. In the first-differences estimator, the instrumental variables are the levels of the period $t-2, t-3$ and $t-4$ for employee crime, unemployment, wage and no educational qualifications. Age is treated as exogenous and is instrumented by itself. In the system estimator, the crime equation in first-differences is estimated jointly with the crime equation in levels. The instrumental variables for the first-differenced equation are the levels of the period $\mathrm{t}-2, \mathrm{t}-3$ and $\mathrm{t}-4$ for lagged employee crime, unemployment, wage and no educational qualifications. The instrumental variables for levels equation are the first-differences for the period $t-1$ for lagged employee crime, unemployment, wage and no educational qualifications. Additional instruments used are the first-difference and level of age.

8. The test of the over-identifying restrictions, called a Sargan test, is asymptotically distributed as $\chi_{(n-p)}^{2}$, where $n$ is the number of instruments and $p$ is the number of parameters, under the null of instrument validity. Degrees of freedom reported in parentheses. 